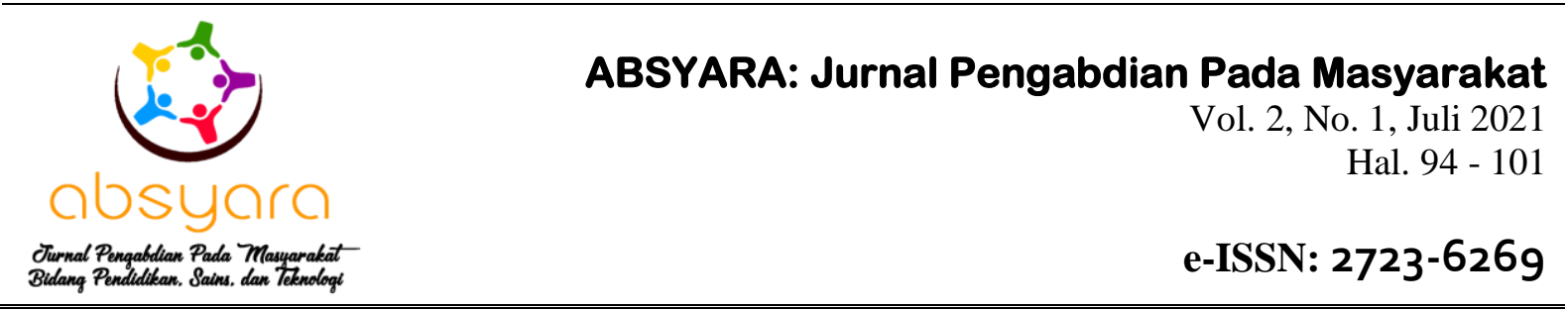

\title{
Pelatihan Online Penerapan Teknologi RADIUS pada PT. Taspen (Persero) Palembang
}

\author{
Rahmat Novrianda Dasmen*1, Ade Putra ${ }^{2}$, Rasmila $^{3}$, Taqrim Ibadi ${ }^{4}$ \\ rahmat.novrianda.d@gmail.com*1 \\ ${ }^{1}$ Program Studi Teknik Komputer, Fakultas Vokasi, Universitas Bina Darma \\ ${ }^{2}$ Program Studi Komputerisasi Akuntansi, Fakultas Vokasi, Universitas Bina Darma \\ ${ }^{3}$ Program Studi Teknik Informatika, Fakultas Ilmu Komputer, Universitas Bina Darma \\ ${ }^{4}$ Program Studi Sistem Informasi, Fakultas Ilmu Komputer, Universitas Bina Darma
}

Received: 31 Mei 2021

DOI: 10.29408/ab.v2i1.3581
Accepted: 26 Juli $2021 \quad$ Online Published: 31 Juli 2021

URL: http://dx.doi.org/10.29408/ab.v2i1.3581

\begin{abstract}
Abstrak: Keaman jaringan internet dalam suatu perusahan sangat penting. Saat ini penggunaan perangkat wireless sebagai pengatur lalu lintas data secara lokal sangat banyak digunakan. Akan tetapi alat ini rentan terjadi pembobolan keamanan jaringan jika tidak dibarengi dengan pengamanan sistem jaringannya yang baik. PT. Taspen (Persero) Palembang, yang mana memiliki permasalahan pada jaringan Wireless dan tidak memiliki pengaman yang baik. Hal ini mengakibatkan pengguna yang tidak termasuk karyawan dapat menggunakan jaringan internet di perusahan tersebut. Sehingga kualitas jaringan wireless untuk operasional karyawan menjadi lambat dan juga rentan akan pembobolan. Oleh karena itu, pada kegiatan PKM ini diterapkanlah Teknologi RADIUS sebagai pengamanan jaringan internal sehingga setiap pengguna yang ingin mengakses jaringan internet di perusahan tersebut harus login terlebih dahulu. Kegiatan ini bertujuan untuk melatih karyawan PT. Taspen (Persero) Palembang untuk mengakses jaringan wifi yang menggunakan Teknologi RADIUS (Remote Access Dial In User Service). Mulai dari mengakses jaringan wifi, login, sampai proses logout dari jaringan wifi. Kegiatan ini dilakukan secara daring dengan memanfatkan aplikasi Zoom Meeting. Hasil yang didapat menunjukkan bahwa kemanan sistem jaringan PT. Taspen (Persero) meningkat dan semua karyawannya dapat mengakses jaringan wifi yang telah menerapkan Teknologi RADIUS.
\end{abstract}

Kata Kunci: Jaringan Wireless, Keamanan Sistem Jaringan; Remote Access Dial In User Service; Teknologi RADIUS

\begin{abstract}
Internet network security in a company is critical. Currently, the use of wireless devices as a local data traffic controller is very widely used. However, this tool is vulnerable to network security breaches if it is not accompanied by excellent security of the network system. PT. Taspen (Persero) Palembang has problems with the Wireless network and does not have an excellent security system. It causes users who are not employees to use the internet network at the company, making employee operations slow and vulnerable to burglary. Therefore, in this PKM activity, RADIUS Technology is applied as internal network security. Every user who wants to access the internet network at the company must first log in. This activity aims to train employees of PT. Taspen (Persero) Palembang to access a wifi network that uses RADIUS Technology. It starts from accessing the wifi network, logging in, to logging out of the wifi network. This activity is carried out online by utilizing the Zoom Meeting application. The results obtained indicate that the network system security of PT. Taspen (Persero) is increasing, and all of its employees can access a wifi network that has implemented RADIUS Technology.
\end{abstract}

Keyword: Network System Security; RADIUS Technolgy; Remote Access Dial In User Service; Wireless Network; 
Dasmen, R. N., Putra, A., Rasmila, R., \& Ibadi, T. (2021). Pelatihan online penerapan teknologi RADIUS pada PT. Taspen (Persero) Palembang. ABSYARA: Jurnal Pengabdian Pada Masyarakat, 2(1), 94-101. doi:10.29408/ab.v2i1.3581

\section{PENDAHULUAN}

PT. Taspen (Persero) Palembang merupakan salah satu BUMN, yang melayani 2 program yaitu Pensiun PNS dan Tabungan Hari Tua. Perusahaan ini telah menerapkan jaringan wireless akan tetapi belum memiliki otentikasi login sehingga siapapun dapat terhubung dalam jaringan wireless tersebut. Hal ini juga mempengaruhi operasional karyawan PT. Taspen (Persero) Palembang yang terganggu dikarenakan kecepatan internet yang lambat akibat padatnya user yang terhubung ke dalam jaringan wireless. Oleh karena itu, pada kegiatan ini dilakukan pengembangan jaringan wireless dengan memberikan otentikasi yang berbeda-beda untuk masing-masing user karyawan (Dasmen, 2018). Adapun pengembangan jaringan wireless ini dengan menerapkan menerapkan Teknologi RADIUS (Remote Access Dial In User Service) (Dasmen, 2017). Teknologi ini berperan sebagai otentikasi user pada jaringan wireless (Kuswanto, 2017). Selain itu, Teknologi RADIUS juga dapat menganalisis penggunaan bandwidth saat diluar jam kerja (Zendrato, 2016). Selain itu dapat juga melakukan pengalokasian bandwidth dengan optimal (Putra \& Pratama, 2019). Keseluruhan konfigurasi untuk Teknologi RADIUS ini memanfaatkan Mikrotik yang telah dimiliki oleh PT. Taspen (Persero) Palembang (Mardiyana, 2015). Dengan otentikasi user dapat membatasi user yang terhubung pada jaringan wireless (Alfred \& Chandra, 2018).

Oleh karena itu, Tim PKM menerapkan Teknologi RADIUS pada jaringan wireless PT. Taspen (Persero) Palembang. Akan tetapi, teknologi RADIUS yang belum pernah digunakan oleh PT. Taspen (Persero) Palembang menyebabkan kesulitan bagi karyawan terutama staf IT untuk memahami tentang penggunaan, pemeliharaan serta pengembangan teknologi tersebut, Untuk mengatasi hal tersebut, dilakukan Pelatihan Online menggunakan Aplikasi Live Zoom Meeting agar user (karyawan) dapat memahami tentang penggunaan login yang dibangun oleh Teknologi RADIUS ini. Selain itu, Tim juga memberikan wadah bagi karyawan khususnya staf IT untuk dapat melakukan diskusi serta konsultasi mengenai Teknologi RADIUS ini hingga seluruh karyawan sudah benar-benar memahami penggunaannya.

\section{METODE PELAKSANAAN}

\section{Waktu dan Lokasi}

Kegiatan Pelatihan Online ini dilakukan menggunakan aplikasi Live Zoom Meeting dari tanggal 8 - 10 Desember 2020 pada PT. Taspen (Persero) Palembang.

\section{Prosedur pelaksanaan}

Adapun tahapan pelaksanaan kegiatan PKM pada PT. Taspen (Persero) Palembang ini menerapkan metode Direct Action (Rasmila \& Amalia, 2019). Pada metode ini semua keadaan yang terjadi dideskripsikan bersamaan dengan tujuan untuk memperbaharui serta mengembang luaskan keadaan yang terjadi saat ini (Dasmen, 2018). Berikut ini merupakan gambar diagram dari metode Direct Action (Chandra \& Amalia, 2019) : 


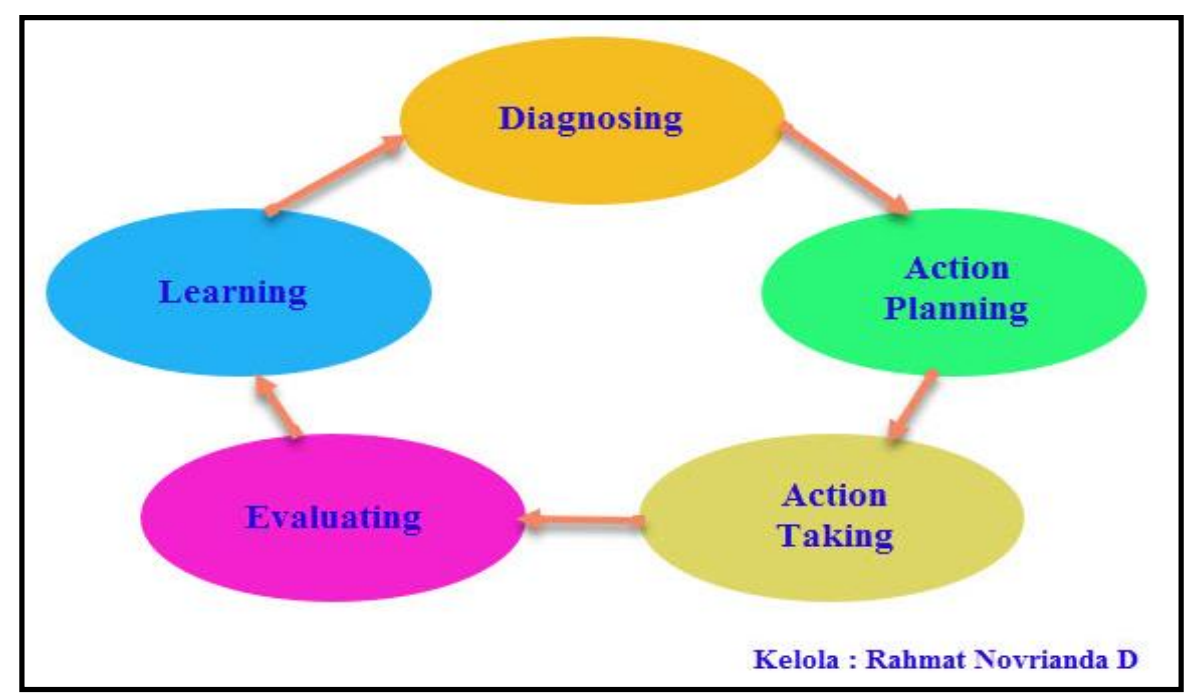

Gambar 1. Metode Direct Action (Dasmen \& Rasmila, 2019)

1. Diagnosing

Tim melakukan survei serta observasi pada PT. Taspen (Persero) Palembang, dimana terdapat permasalahan dalam penggunaan jaringan wireless PT. Taspen (Persero) Palembang. Adapun permasalahannya adalah siapa saja dapat terhubung ke dalam jaringan wireless tersebut sehingga traffic user menjadi padat. Hal ini menyebabkan kecepatan internet untuk operasional menjadi lambat dan mempengaruhi kinerja.

2. Action Planning

Dari permasalahan yang diperoleh, Tim PKM merencanakan suatu solusi untuk pengembangan jaringan wireless PT. Taspen (Persero) Palembang sehingga memiliki suatu halaman login tersendiri sebelum user terhubung ke dalam jaringan wireless tersebut.

3. Action Taking

Adapun dari perencanaan sebelumnya Teknologi yang dapat diterapkan adalah Teknologi. RADIUS. Oleh karena itu, Tim PKM melakukan penerapan Teknologi RADIUS pada jaringan wireless PT. Taspen (Persero) Palembang untuk dapat membangun otentikasi dengan memberikan masing-masing username dan password yang berbeda-beda pada user (karyawan).

4. Evaluating

Pada tahapan ini, Tim PKM melakukan Pelatihan Online kepada karyawan PT. Taspen (Persero) Palembang mengenai Teknologi RADIUS tersebut.

5. Learning

Tahapan ini merupakan tahapan terakhir dalam prosedur pelaksanaan kegiatan, dimana pada tahapan ini diberikan juga pemahaman kepada peserta Pelatihan Online secara lengkap tentang Teknologi RADIUS, cara penggunaannya serta cara perawatan dan pengembangannya 


\section{HASIL DAN PEMBAHASAN \\ HASIL}

Adapun sebelum dilakukan Pelatihan Online, Tim PKM telah membangun sistem otentikasi login dengan Teknologi RADIUS untuk diterapkan pada jaringan wireless PT. Taspen (Persero) Palembang. Kemudian, dilakukanlah Pelatihan Online dengan memafaatkan Aplikasi Live Zoom Meeting seperti pada gambar di bawah ini:

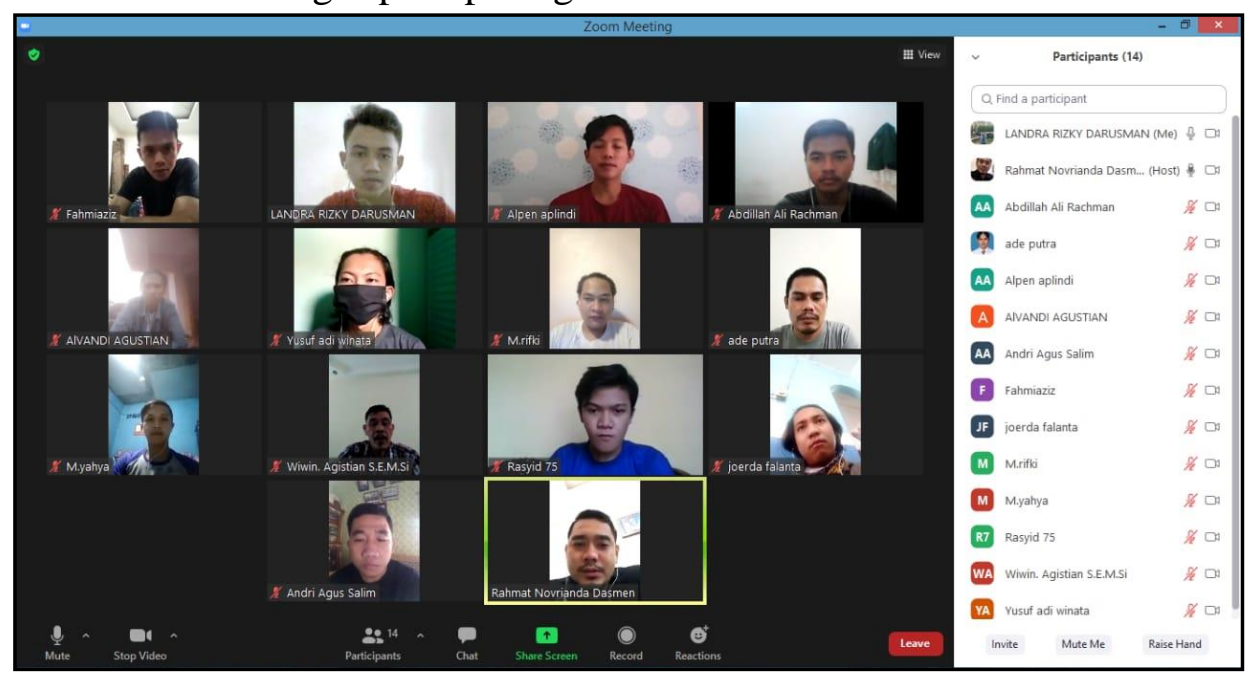

Gambar 2. Pelatihan Online dengan Live Zoom Meeting

Dari hasil Pelatihan Online yang telah Tim PKM laksanakan, maka diperolehlah beberapa karyawan yang telah membuat username dan passwordnya untuk dapat terhubung ke dalam jaringan wireless PT. Taspen (Persero) Palembang. Adapun berikut ini merupakan beberapa hasil username dan password yang berhasil dibuat pada saat Pelatihan Online dilakukan:

Tabel 1. Tabel Username dan Password Karyawan

\begin{tabular}{cccc}
\hline No. & Ruangan & Username & Password \\
\hline 1. & & krismanto & Kr1sm@nt0 \\
2. & Lantai 1 Ruang & agung & A6un9 \\
3. & Pelayanan & herwannurdin & H3rw@nnurd1n \\
4. & & desri & D3sr1 \\
5. & Lantai 2 Ruang & toto karyono & Tot0k@ry0no \\
6. & Keuangan & Suyono & Suy@n0 \\
7. & & agnes s & Agn35 \\
\hline
\end{tabular}

Selanjutnya, dilakukan juga pengujian terhadap penggunaan username dan password yang telah dibuat. Adapun pengujian ini dilakukan dengan 2 perangkat yaitu Smartphone dan Personal Computer. Berikut ini merupakan hasil pengujian login terhadap jaringan wireless PT. Taspen (Persero) Palembang: 


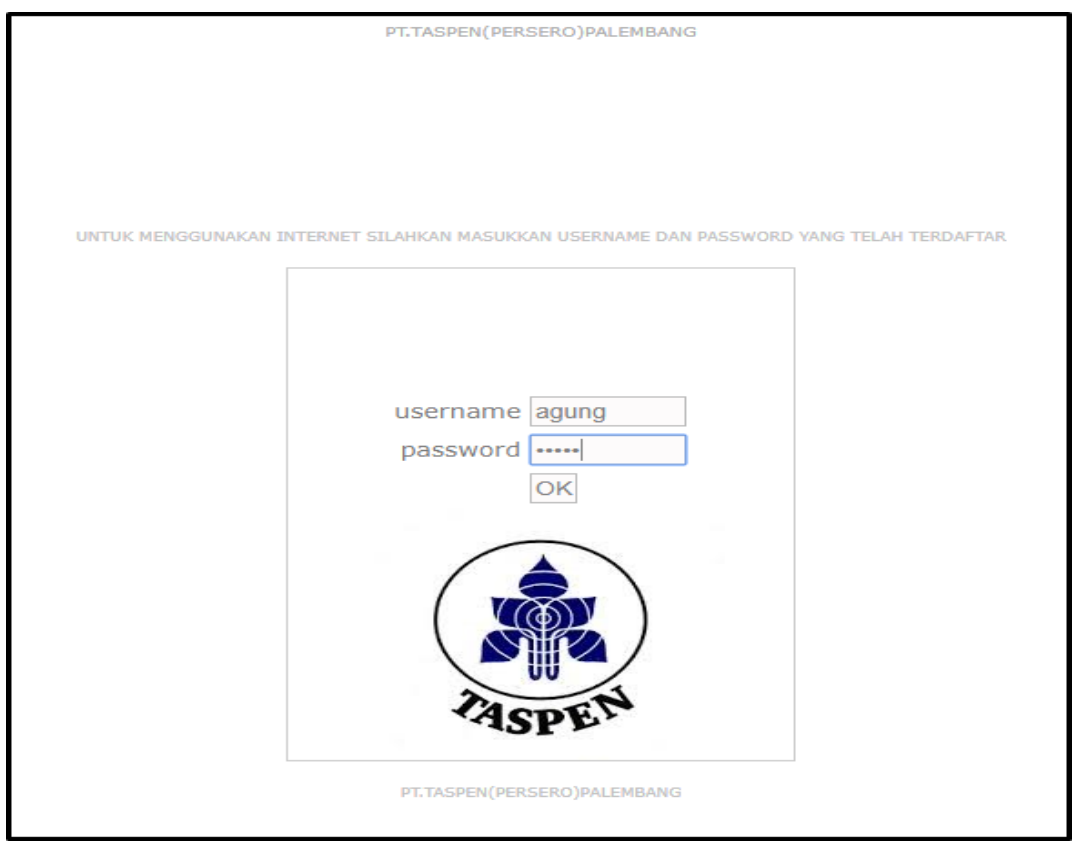

Gambar 3. Halaman login user menggunakan Smartpone

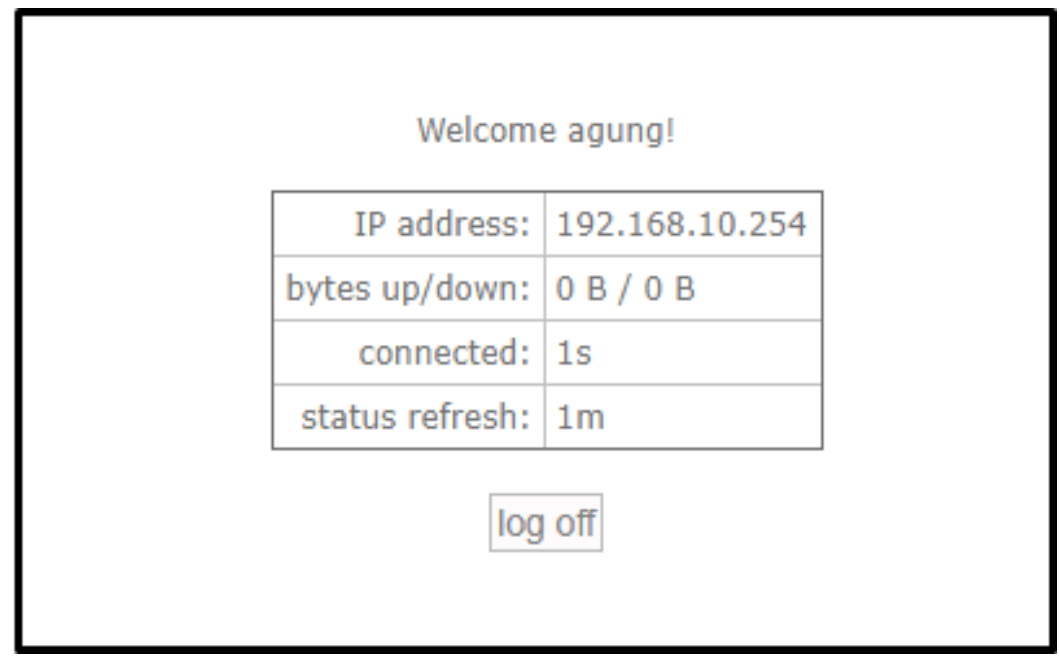

Gambar 4. Login user menggunakan Smartphone berhasil 


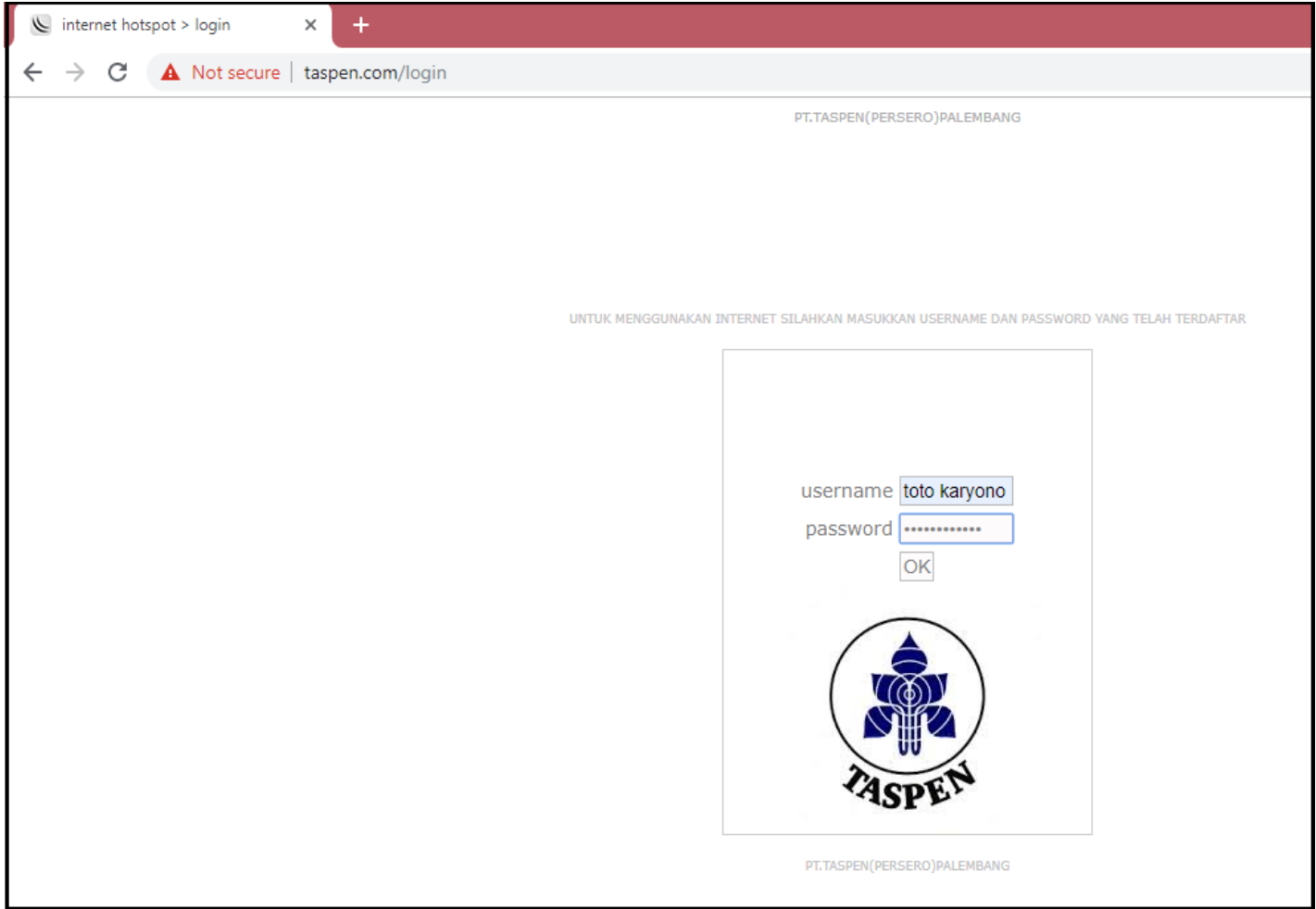

Gambar 5. Halaman login user menggunakan Personal Computer

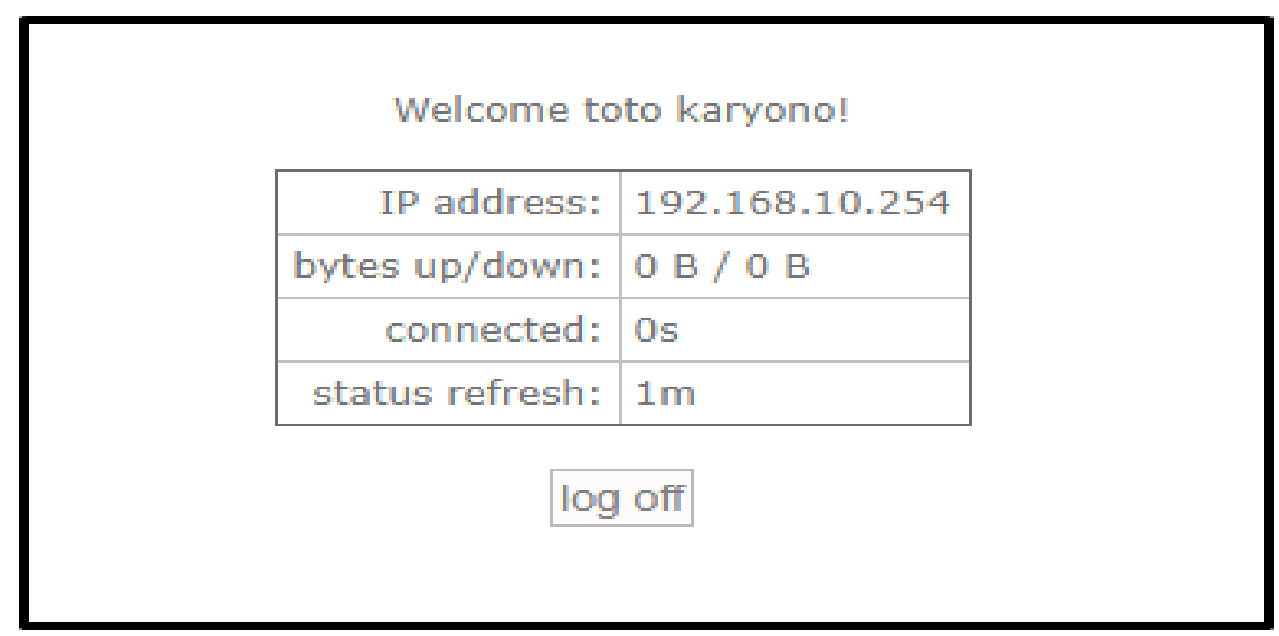

Gambar 6. Login user menggunakan Personal Computer berhasil

\section{PEMBAHASAN}

Dari hasil pengujian yang dilakukan saat Pelatihan berlangsung, dapat dipantau bahwa Peserta Kegiatan PKM ini telah memahami cara login pada Teknologi RADIUS. Akan tetapi, untuk staf IT masih perlu diberikan pelatihan tambahan untuk pemahaman tentang Teknologi RADIUS, cara pemeliharaannya hingga perencanaan dalam pengembangan Teknologi RADIUS ini agar menopang kebutuhan keamanan jaringan wireless pada PT. Taspen (Persero) Palembang. Beberapa karyawan telah mampu membuat username dan passwordnya masingmasing dan juga telah dilakukan pengujian untuk login terhubung ke dalam jaringan wireless PT. Taspen (Persero) Palembang. 
Dasmen, R. N., Putra, A., Rasmila, R., \& Ibadi, T. (2021). Pelatihan online penerapan teknologi RADIUS pada PT. Taspen (Persero) Palembang. ABSYARA: Jurnal Pengabdian Pada Masyarakat, 2(1), 94-101. doi:10.29408/ab.v2i1.3581

\section{SIMPULAN}

Adapun beberapa simpulan yang dapat ditarik dari hasil kegiatan PKM yang telah dilaksanakan yaitu penerapan Teknologi RADIUS pada jaringan wireless PT. Taspen (Persero) Palembang sehingga terbentuk halaman login tersendiri sebelum terhubunga pada jaringan wireless tersebut. Tidak hanya itu, pada kegiatan ini juga dilakukan Pelatihan Online dimana beberapa karyawan telah memperoleh username dan passwordnya sehingga dapat diuji untuk akses login pada jaringan wireless PT. Taspen (Persero) Palembang. Selain itu, pada pelatihan online juga dijelaskan secara lengkap tentang Teknologi RADIUS, cara membangunnya, cara penggunaannya serta cara perawatan ataupun pengembangannya. Adapun dapat dipersentasikan bahwa seluruh peserta pelatihan telah memahami cara login pada Teknologi RADIUS, tetapi untuk staf IT masih memerlukan pelatihan khusus dan lebih mendalam tentang pemeliharaan serta pengembangan Teknologi RADIUS.

\section{PERNYATAAN PENULIS}

Artikel ini merupakan hasil karya sendiri yang belum pernah dipublikasikan baik secara keseluruhan maupun sebahagian, dalam bentuk jurnal, working paper atau bentuk lain yang dipublikasikan secara umum. Karya ilmiah ini sepenuhnya merupakan karya intelektual dan seluruh sumber yang menjadi rujukan dalam karya ilmiah ini telah sebutkan sesuai kaidah akademik yang berlaku umum, termasuk para pihak yang telah memberikan kontribusi pemikiran pada isi, kecuali yang menyangkut ekspresi kalimat dan disain penulisan.

\section{DAFTAR PUSTAKA}

Alfred, A., \& Chandra, J. C. (2018). Pemanfaatan Firewall pada jaringan komputer SMK Fadilah. IDEALIS: InDonEsiA journaL Information System, 1(5), 422-428.

Chandra, W., \& Amalia, R. (2019). Sistem Informasi pemesanan kamar mess PT. KAI Persero Divre III Sumatera Selatan. CESS (Journal of Computer Engineering, System and Science), 4(1), 88-93.

Dasmen, R. N. (2017). Rancang bangun keamanan jaringan wireless pada STIPER Sriwigama Palembang dengan RADIUS Server. Jurnal Maklumatika, 4(1), 19-29.

Dasmen, R. N. (2018). Implementasi authentication Captive Portal pada Wireless Local Area Network PT. Rikku Mitra Sriwijaya. Register: Jurnal Ilmiah Teknologi Sistem Informasi, 4(2), 67-80.

Dasmen, R. N. (2018). Implementasi Raspberry Pi 3 sebagai Wireless Access Point pada STIPER Sriwigama Palembang. Jurnal Informatika: Jurnal Pengembangan IT, 3(3), 387-393.

Dasmen, R. N. (2019). Implementasi Raspberry Pi 3 pada Sistem Pengontrol Lampu berbasis Raspbian Jessie. JEPIN (Jurnal Edukasi dan Penelitian Informatika), 5(1), 46-53.

Kuswanto, H. (2017). Sistem Autentikasi Hotspot menggunakan RADIUS Server Mikrotik Router. INFORMATICS FOR EDUCATORS AND PROFESSIONAL: Journal of Informatics, 2(1), 43-50. 
Mardiyana, I. G. K. O. (2015). Keamanan jaringan dengan Firewall Filter berbasis Mikrotik pada Laboratorium Komputer STIKOM Bali. Proceedings Konferensi Nasional Sistem dan Informatika (KNS\&I).

Putra, I. G. B. P., \& Pratama, I. P. A. E. (2019). Optimasi Radius Server untuk Pengaturan alokasi Bandwidth pada Jaringan Hotspot. JUSS (Jurnal Sains dan Sistem Informasi), 2(2), 18-24.

Rasmila, R., \& Amalia, R. (2019). Sistem informasi penentuan persiapan stok obat menggunakan Weighted Moving Average. Sistemasi: Jurnal Sistem Informasi, 8(3), 465-478.

Zendrato, N. (2016). Analisis pemanfaatan Bandwith Pada Off-Time kantor menggunakan Mikrotik dan Radius Server. Sinkron: jurnal dan penelitian teknik informatika, 1(1), 25-29. 